\title{
Radial Shock Waves in the Treatment of Pseudoarthrosis
}

ISSN: 2576-8875

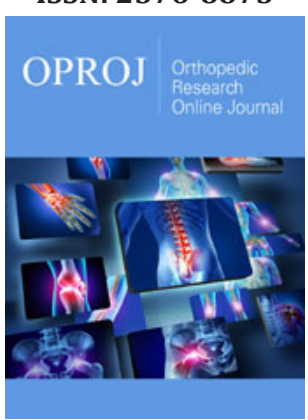

*Corresponding author:Paulo Kertzman, Department of Orthopedics, Santa Casa De Sao Paulo, Brazil

Submission: 制 December 02, 2018

Published: 眥December 06, 2019

Volume 6 - Issue 2

How to cite this article: Paulo K, Patricia MB. Radial Shock Waves in the Treatment of Pseudoarthrosis. Ortho Res Online J. 6(2). OPROJ.000634.2019.

DOI: 10.31031/OPROJ.2019.06.000634

Copyright@: Paulo Kertzman, This article is distributed under the terms of the Creative Commons Attribution 4.0 International License, which permits unrestricted use and redistribution provided that the original author and source are credited.

\author{
Paulo Kertzman* and Patricia MB \\ Department of Orthopedics, Santa Casa De Sao Paulo, Brazil
}

\begin{abstract}
In this work we will analyze an innovative method using radial shock waves for the treatment of pseudarthrosis in superficial bones, avoiding surgical treatment that is usual for these cases. Treatment with shock waves promotes consolidation by stimulating osteoblasts and tissue regeneration factors, without the need for further surgery, reducing risks for patients. Forty consecutive cases were treated between June 2016 and December 2018. All patients had received indication for surgical treatment to correct the consolidation failure and therefore no control group or use of placebo treatment was made so as not to harm patients. Twenty-two men and 18 women were treated, ranging from 18 to 83 years with an average of 30.2 years. The mean time between the beginning of treatment with radial Shock Waves and the last treatment of the fracture was 8.8 months ranging from 6 to 38 months. In each session, 3000 radial waves were applied, the first 500 with 2 pressure bar for analgesia and 2500 waves with 4 bar for effective treatment. The site of the application of radial shock waves was determined by radiographs. Treatment was performed in an outpatient clinic without the need for hospitalization or anesthesia. Patients were reevaluated with radiographs after treatment in the periods of 2.4 and 6 months. The criterion for evaluation was radiographs evidencing.
\end{abstract}

\section{Introduction}

In this paper, we performed an innovative method, little described in the literature, using the radial shock waves for the treatment of pseudoarthrosis in superficial bones. Despite the current concepts in the surgical treatment of fractures with minimally invasive techniques and better fixation, about three to fifteen percent of cases involve to failed consolidation, being considered a pseudarthrosis after six months of the initial trauma without signs consolidation on the last 3 months [1]. The treatment usually recommended in these cases is the exchange of the osteosynthesis material and placement of bone graft, often evolved with good results, however, in addition to the high cost, there may be complications such as pain, bleeding, hematoma, infection, and consolidation failed [2].

The treatment of pseudoarthrosis using focal extracorporeal shock waves as an option to conventional surgical treatment has shown good results [3]. Treatment with extracorporeal shock waves is shown to stimulate the consolidation without the need for a new surgery, reducing risks and costs when the reason for failure of consolidation is of biological origin and not of instability mechanics, and the defect is smaller than $5 \mathrm{~mm}$ in long bones [4-7]. The treatment of pseudoarthrosis with shock waves should be carried out preferably with socalled focus shock waves by applying high energy. We started our practice in 1999 using this concept with good results [8]. Based on the good results obtained with the use of radial waves in tendinopathies [8] and the positive effect in vitro on osteoblasts and in vivo $[9,10]$ and due to the difficulty of access to equipment generators high energy focal shock waves in Brazil, in 2009 we began the use radial shock waves to cases of superficial bones pseudoarthrosis. We started the treatment with radial shock waves in specific cases of superficial bones and published in 2017 a series of 22 cases being the highest in international literature [10]. We decided to do a series of prospective cases to confirm these good results. In this paper, we analyze the differences between the two types of waves, how the focal and radial shock waves are operating in pseudoarthrosis and if radial shock waves are effective.

\section{Patients and Methods}

This study was approved by the Research Ethics Committee of the Santa Casa Medical School and Hospitals, São Paulo, Brazil, under the number 12558513.1.000.5479. Prospective 
analysis of 40 consecutive cases treated between June 2016 and December 2018. Inclusion criteria were superficial bone not consolidated with at least six months, bone defect less than five millimeters and provide mechanical stability in the fracture focus. The exclusions have followed the standards of the Brazilian Society of Extracorporeal Shock Wave Treatment: use of anticoagulant, pregnant women, the presence of open physics in children and local tumor in addition to failure in fracture stabilization and larger defects of five millimeters.

All patients had the diagnostic confirmed for orthopedic surgeons as a pseudoarthrosis and received indication for performing surgical treatment for the correction of the failure of consolidation. We offer the treatment with radial ESWT as an option to surgery and, therefore, not been done nor control group or placebo treatment not to harm patients. We treated consecutive 40 patients, 22 men and 18 women, with age ranging from 18 to 83 years-old with an average of 30.2 years. The tibia was the most affected bone with 13 cases, followed by metatarsals in 7 cases, 4 distal humerus, 4 ulna, 2 calcaneus, 1 talus, 2 ischio, 2 fibula, 2 clavicle, 1 radio, 1 navicular, 1 scaphoid. The average time between the start of treatment with radial shock waves and the initial fracture was 8.8 months ranging from 6 to 38 months. All were treated by the same doctor and same equipment with 3 weekly interval sessions. In each session were applied radial waves 3000 being the first 500 with 2 bar pressure for analgesia and 2500 waves with 4 bar for effective treatment. X-rays and palpation of the failed site consolidation determined the location of the application of the radial shock waves. The treatment was carried out on an outpatient basis without the need for hospitalization or anesthesia. After the sessions of treatment in cases of lower limb compromise were kept walking with crutches with the same load and in 5 cases where there was no prior osteosynthesis patients used immobilization for 4 weeks. Patients were evaluated with radiographs after treatment during periods of 2.4 and 6 months.

\section{Results}

After 6 months of treatment the radiographic consolidation in $31(77.5 \%)$ and in 9 patients $(22.5 \%)$ there was no healing. All patients reported pain of medium intensity during application of radial shockwaves but there was no stopping treatment due to pain and all reported improvement after the session, without major worsening in the following days (Table 1).

Table 1

\begin{tabular}{|c|c|c|c|c|c|c|c|c|}
\hline Number & Age & Gender & Bone & $\begin{array}{c}\text { Last } \\
\text { treatment }\end{array}$ & Interval & $\begin{array}{l}\text { Previous } \\
\text { Surgery }\end{array}$ & $\begin{array}{c}\text { First Radilal } \\
\text { Treatment }\end{array}$ & Result \\
\hline 1 & 46 & fem & clavicula & Aug-15 & 6 & no cir & Feb-16 & pos \\
\hline 2 & 59 & mas & phibula & Dec-15 & 6 & 1 & May-16 & pos \\
\hline 3 & 56 & mas & tibia & Aug-15 & 9 & 2 & May-16 & pos \\
\hline 4 & 61 & fem & calcaneus & Dec-15 & 6 & 1 & Jun-16 & pos \\
\hline 5 & 19 & mas & tibia & May-15 & 11 & 1 & Jun-16 & pos \\
\hline 6 & 69 & mas & tibia & May-15 & 11 & 2 & Jun-16 & neg \\
\hline 7 & 37 & mas & ulna & Mar-16 & 6 & 1 & Sep-16 & pos \\
\hline 8 & 45 & fem & tibia & Feb-16 & 8 & 2 & Oct-16 & pos \\
\hline 9 & 61 & fem & ulna & Mar-16 & 7 & 1 & Oct-16 & pos \\
\hline 10 & 26 & mas & tibia & Aug-13 & 38 & 2 & Oct-16 & neg \\
\hline 11 & 43 & fem & metatarsus & Apr-16 & 7 & no cir & Nov-16 & pos \\
\hline 12 & 41 & mas & umero & Mar-16 & 8 & 1 & Nov-16 & neg \\
\hline 13 & 31 & mas & ulna & Feb-15 & 10 & 1 & Dec-16 & pos \\
\hline 14 & 82 & mas & tibia & Jan-16 & 12 & 2 & Dec-16 & pos \\
\hline 15 & 42 & fem & tibia & Aug-15 & 7 & 2 & Mar-17 & pos \\
\hline 16 & 50 & fem & úmero & Dec-16 & 11 & 1 & Nov-17 & neg \\
\hline 17 & 19 & mas & metatarsus & Feb-17 & 9 & no cir & Nov-17 & pos \\
\hline 18 & 53 & mas & umero & Jan-17 & 10 & 1 & Nov-17 & neg \\
\hline 19 & 83 & fem & ulna & Mar-17 & 9 & 1 & Dec-17 & pos \\
\hline 20 & 72 & fem & metatarsus & Apr-17 & 8 & 2 & Dec-17 & pos \\
\hline 21 & 45 & fem & radio & Jun-17 & 6 & 1 & Dec-17 & neg \\
\hline 22 & 45 & masc & umero & Dec-17 & 12 & 1 & Dec-17 & pos \\
\hline 23 & 64 & fem & fibula & Sep-17 & 8 & no cir & Apr-18 & pos \\
\hline 24 & 63 & fem & metatarsus & May-17 & 11 & 1 & Apr-18 & pos \\
\hline 25 & 55 & mas & calcaneus & Feb-17 & 10 & 3 & Apr-18 & pos \\
\hline 26 & 71 & mas & tibia & Dec-17 & 6 & 1 & May-18 & pos \\
\hline
\end{tabular}




\begin{tabular}{|l|l|l|l|l|l|l|l|c|}
\hline 27 & 54 & fem & metatarsus & Jul-17 & 9 & 1 & May-18 & pos \\
\hline 28 & 18 & fem & ísquio & Jun-17 & 9 & no cir & May-18 & neg \\
\hline 29 & 57 & mas & tibia & Nov-17 & 7 & 1 & May-18 & pos \\
\hline 30 & 60 & fem & tibia & Dec-17 & 6 & 1 & Jun-18 & jos \\
\hline 31 & 71 & fem & tibia & Nov-17 & 7 & 1 & neg \\
\hline 32 & 50 & fem & isquio & Nov-17 & 9 & no cir & Aug-18 \\
\hline 33 & 18 & mas & scaphoide & Nov-17 & 9 & 1 & Aug-18 & nov-18 \\
\hline 34 & 59 & mas & tibia & Mar-18 & 8 & 1 & pos \\
\hline 35 & 34 & fem & metatarsus & Apr-18 & 7 & 1 & Nov-18 & pos \\
\hline 36 & 33 & fem & talus & Jan-18 & 10 & 1 & Nov-18 & pos \\
\hline 37 & 34 & masc & navicular & May-18 & 6 & 1 & pov-18 \\
\hline 38 & 46 & mas & clavicula & Jun-18 & 6 & no cir & Dec-18 & pos \\
\hline 39 & 49 & masc & metatarsus & Jun-18 & 6 & no cir & Dec-18 & pos \\
\hline 40 & 37 & masc & tibia & Jun-18 & 6 & no cir & Dec-18 & pos \\
\hline
\end{tabular}

After 6 months of the treatment, all 31 patients with positive results was free of pain and satisfied with the treatment. The patients with bad results were submitted to surgical treatment. As adverse events, occurred edema, bruising and redness in 18\% of cases with spontaneous resolution in a few days. There was no major complication or additional treatment needed.

\section{Discussion}

In this paper we analyze the literature on some issues that still generate doubts and also our results with this new technique.

A. What are shock waves and the mechanism of action in pseudarthrosis?

B. When should we apply the shock wave? The presence of the osteosynthesis hinders or contraindicates the use of shock waves?

C. How many sessions are necessary? Is there difference of results as to the that is equipment used? What level of energy should be used?

D. What is the effectiveness? Are there complications with the shock wave treatment?

E. It is possible to treat pseudoarthrosis with radial shock waves?

\section{What are shock waves and which the action in the bones?}

Focal and radial shock waves are mechanical waves high intensity sound produced by specific equipment being characterized in terms of physical and high-intensity and quick wave length containing a positive initial phase followed by a make less negative. What differentiates the two types of waves, is minor duration and intensity, and the peak energy is approximately a centimeter deep on radial waves [11]. When we use the focal waves, we could program the place of maximum energy that reaches the tissue to be treated between 0.5 and $5 \mathrm{~cm}$ deep, whereas with radial waves is more superficial between 0.5 and 1.5 [12].
Both the focal as the radial waves are able to stimulate the activity of osteoblasts in vitro as in both animals. Both promote an effect called cavitation, that is related to the stimulus to consolidation of pseudoarthrosis through a phenomenon described as mechanotransduction, in which a mechanical stimulus induces a series of biological reactions by stimulating the production of bone regeneration, increased vascularization and bone matrix production by osteoblasts. [12-16] Focus shock waves are produced by generators that were initially developed for urological treatment of lithiasis, and may be hydraulic, piezoelectric or magnetic. Radial shock waves are produced by pneumatic or magnetic generators [17]. By accident there was the stimulation of the iliac crest in patients treated of ureteral lithiasis who developed a reaction the periosteum of the iliac wing. Since 1981 were developed studies on this unexpected action [18].

At the beginning it was believed only in a mechanical action causing stimulation of the periosteum, but animal studies and clinical trials have shown a series of chemical reactions by stimulating the production of osteoblasts, and tissue regeneration factors increase factors the vascularity that explain the consolidation of pseudoarthrosis and consolidation delays after stimulation with shock waves [19]. These biological actions occur at the time of application with intense stimulation of the periosteum and the following days with increasing concentration of prostaglandins, local factors of tissue regeneration and increased local vascularization factor that can last for up to six months is the average time for consolidation to occur [18-22]. Works on animals demonstrate the stimulus in osteoblasts and bone callus formation of good quality and endurance using both focal and radial waves $[21,15]$.

\section{When should we apply the shock wave? The presence of the osteosynthesis hinders or contraindicates the use of shock waves?}

The indication is for cases of delayed consolidation or pseudarthrosis biological failure, when the space between the fragments is up to $5 \mathrm{~mm}$ in long bones and it is necessary that there 
is mechanical stability in the fracture focus [22]. The presence of plates, screws, rods and external fixators is no contraindication, because there's no heat reaction or risk of loosening due to mechanical stimulus, on the contrary, the presence of osteosynthesis is required so that there is stability of the focus of pseudarthrosis and allow healing. The doctor must take care to direct the waves in such a way that there are between the generator and the bone the presence of metal plate which can prevent the progression of energy preventing action on your bone to be treated. If there is a failure in stability is necessary to correct with new or use of osteosynthesis immobilization [23].

How many sessions are necessary? Is there difference of results as to the that is equipment used? What level of energy should be used?

There is still a lack of standardization of the treatment on the number of sessions and energy used for each type of pseudarthrosis, which makes the comparison among the papers published difficult. However, most authors use the same energy dosage and number of waves in all kinds of bones being applied on average 3000 shockwaves to each session ranging from one to three sessions [2426]. Treatment with high energy and deep focal waves is usually done under anesthesia and can be repeated after 4 to 6 weeks of the first stimulus and the majority of patients receives two to three sessions. The energy used ranges from 0.18 to 0.30 millijoules per square millimeter. The best results are with hydraulic generators and magnetic equipment $[25,26]$. To treat with radial waves not using anesthesia and are made at least three sessions with an interval of a week with 3000 waves each session applied directly to the focus of pseudarthrosis with 4 energy bar which is equivalent to 0.18 to 0.20 millijoules per mm square meter.

\section{What is the effectiveness? Are there complications with the shock wave treatment?}

The best results are reported with the use of focal ESWT generating equipment with hydraulic generators and magnetic, the patient sedated and using fluoroscopy to the location of the point of treatment with 65 to $78 \%$ of good results [27-29]. As to the type of pseudarthrosis best results are to the hypertrophic, but in also reported good results are atrophic. Immobilization after treatment for 6 to 8 weeks may be necessary in cases of greater instability in the focus of pseudarthrosis [29,30].

Most of the works comprises a series of cases, but there are also studies comparing with traditional surgery in the femur, scaphoid and metatarsals. These studies show results similar to surgical treatment, but with much lower cost, morbidity and complications [31-34]. There are review works simple and systematic reviews of the literature confirming the effectiveness of the use of focal shock waves [35-37]. Adverse effects are pain at the time of application that may require the use of general anesthesia or regional blockade. Are reported swelling, petechiae, bruising and superficial pain in the early days after application with good evolution with medical follow-up. There is no report of serious complications with the treatment. [34,35] Is a treatment exclusively orthopedic doctor since it requires an accurate diagnosis, bone pathology knowledge, knowledge of the regional anatomy preventing vessels and nerves and the assessment of the consolidation.

\section{It is possible to treat pseudoarthrosis with radial shock waves?}

There are scientific studies demonstrating the effectiveness of radial waves in vitro, in animals and in humans [15,16,38-42]. Recently there was the use of so-called radial waves to the bone surface treatment with good results [39]. We present in this paper the largest series of prospective cases treated with radial shock waves published in world literature by opening a new line of interest so that other authors can study this new method of treatment.

As weak points, we can consider the small number of cases studied, and the lack of control or placebo group.

The use of radial shock waves for the treatment of superficial bones proved to be a safe, efficient method and less expensive but requires more study to proof of your effectiveness. That new option for treatment of pseudoarthrosis of superficial bones is as effective as surgery and focal ESWT. We believe that this new method of treatment can benefit many patients.

\section{Conclusion}

The use of radial shock waves in cases of pseudarthrosis in superficial bone is effective and safe.

\section{References}

1. Bell A, Templeman D, Weinlein JC (2016) Nonunion of the femur and tibia: An update. Orthop Clin North Am 47(2): 365-375.

2. Rupp M, Biehl C, Budak M, Thormann U, Heiss C, et al. (2018) Diaphyseal long bone nonunions-types, aetiology, economics, and treatment recommendations. Int Orthop 42(2): 247-258.

3. Schaden W, Mittermayr R, Haffner N, Smolen D, Gerdesmeyer L, et al. (2015) Extracorporeal Shockwave Therapy (ESWT)-First choice treatment of fracture non-unions? Int J Surg 24(Pt B): 179-183.

4. Wang CJ, Chen HS, Chen CE, Yang KD (2001) Treatment of nonunions of long bone fractures with shock waves. Clin Orthop Relat Res 387: 95101.

5. Haupt G, Haupt A, Gerety B, Chvapil M (1990) Enhancement of fracture healing with extracorporeal shock waves. J Urol.

6. Valchanou VD, Michailov P (1991) High energy shock waves in the treatment of delayed and nonunion of fractures. Int Orthop 15(3): 181184.

7. Haupt G, Haupt A, Ekkernkamp A, Gerety B, Chvapil M (1992) Influence of shock waves on fracture healing. Urology 39(6): 529-532.

8. Kertzman P, Lenza M, Pedrinelli A, Ejnisman B (2015) Shockwave treatment for musculoskeletal diseases and bone consolidation: Qualitative analysis of the literature. Rev Bras Ortop 50(1): 3-8.

9. Schnurrer LVT, Avancini DV, Sosa I, Cvijanovic O, Bobinac D (2018) Effect of radial shock wave therapy on long bone fracture repair. J Biol Regul Homeost Agents 32(4): 875-879.

10. Gollwitzer H, Gloeck T, Roessner M, Langer R, Horn C, et al. (2013) Radial Extracorporeal Shock Wave Therapy (rESWT) induces new bone formation in vivo: Results of an animal study in rabbits. Ultrasound Med Biol 39(1): 126-133. 
11. Kertzman P, Császár NBM, Furia JP, Schmitz C (2017) Radial extracorporeal shock wave therapy is efficient and safe in the treatment of fracture nonunions of superficial bones: A retrospective case series. J Orthop Surg Res 12(1): 164.

12. Haupt G, Haupt A, Ekkernkamp A, Gerety B, Chvapil M (1992) Influence of shock waves on fracture healing. Urology 39(6): 529-532.

13. Agostino MC, Craig K, Tibalt E, Respizzi S (2015) Shock wave as biological therapeutic tool: From mechanical stimulation to recovery and healing, through mechanotransduction. Int J Surg 24(Pt B): 147-153.

14. Cheng JH, Wang CJ (2015) Biological mechanism of shockwave in bone. Int J Surg 24(Pt B): 143-146.

15. Schnurrer LVT, Avancini DV, Sosa I, Cvijanovic O, Bobinac D (2018) Effect of radial shock wave therapy on long bone fracture repair. J Biol Regul Homeost Agents 32(4): 875-879.

16. Császár NB, Angstman NB, Milz S, Sprecher CM, Kobel P, et al. (2015) Radial shock wave devices generate cavitation. PLoS One 10(10): e0140541.

17. Valchanou VD, Michailov P (1991) High energy shock waves in the treatment of delayed and nonunion of fractures. Int Orthop 15(3): 181184.

18. Wang CJ, Wang FS, Yang KD (2008) Biological effects of extracorporeal shockwave in bone healing: a study in rabbits. Arch Orthop Trauma Surg 128(8): 879-884.

19. Xu JK, Chen HJ, Li XD, Huang H, Xu HL, et al. (2012) Optimal intensity shock wave promotes the adhesion and migration of rat osteoblasts via integrin $\beta 1$-mediated expression of phosphorylated focal adhesion kinase. J Biol Chem 287(31): 26200-26212.

20. Ha CH, Kim S, Chung J, An SH, Kwon K (2013) Extracorporeal shock wave stimulates expression of the angiogenic genes via mechanosensory complex in endothelial cells: Mimetic effect of fluid shear stress in endothelial cells. Int J Cardiol 168 (4): 4168-4177.

21. Sun D, Junger WG, Yuan C, Zhang W, Bao Y, et al. (2013) Shockwaves induce osteogenic differentiation of human mesenchymal stem cells through ATP release and activation of P2X7 receptors. Stem Cells 31(6): 1170-1180.

22. Wang FS, Wang CJ, Chen YJ, Chang PR, Huang YT, et al. (2004) Ras induction of superoxide activates ERK-dependent angiogenic transcription factor HIF-1alpha and VEGF-A expression in shock wavestimulated osteoblasts. J Biol Chem 279(11): 10331-10337.

23. Kusnierczak D, Brocai DR, Vettel U, Loew M (2000) Effect of extracorporeal shockwave administration on biological behavior of bone cells in vitro. Z Orthop 138(1): 29-33.

24. Xu ZH, Jiang Q Chen DY, Xiong J, Shi DQ et al. (2009) Extracorporeal shock wave treatment in non-unions of long bone fractures. Int Orthop 33(3): 789-793.

25. Bara T, Synder M (2007) Nine-years' experience with the use of shock waves for treatment of bone union disturbances. Ortop Traumatol Rehabil 9(3): 254-258.

26. Rompe JD, Rosendahl T, Schöllner C, Theis C (2001) High-energy extracorporeal shock wave treatment of nonunions. Clin Orthop Relat Res 387: 102-111.

27. Wang CJ, Chen HS, Chen CE, Yang KD (2001) Treatment of nonunions of long bone fractures with shock waves. Clin Orthop Relat Res 387: 95101.
28. Schaden W, Fischer A, Sailler A (2001) Extracorporeal shock wave therapy of nonunion or delayed osseous union. Clin Orthop Relat Res 387: 90-94

29. Vulpiani MC, Vetrano M, Conforti F, Minutolo L, Trischitta D, et al. (2012) Effects of extracorporeal shock wave therapy on fracture nonunions. Am J Orthop (Belle Mead NJ) 41(9): E122-127.

30. Kuo SJ, Su IC, Wang CJ, Ko JY (2015) Extracorporeal shockwave therapy (ESWT) in the treatment of atrophic non-unions of femoral shaft fractures. Int J Surg 24(Pt B): 131-134.

31. Schmitz C, Császár NB, Milz S, Schieker M, Maffulli N, et al. (2015) Efficacy and safety of extracorporeal shock wave therapy for orthopedic conditions: A systematic review on studies listed in the PEDro database. Br Med Bull 116: 115-138.

32. Cacchio A, Giordano L, Colafarina O, Rompe JD, Tavernese E, et al. (2009) Extracorporeal shock-wave therapy compared with surgery for hypertrophic long-bone nonunions. J Bone Joint Surg Am 91(11): 25892597.

33. Furia JP, Juliano PJ, Wade AM, Schaden W, Mittermayr R (2010) Shock wave therapy compared with intramedullary screw fixation for nonunion of proximal fifth metatarsal metaphyseal-diaphyseal fractures. J Bone Joint Surg Am 92(4): 846-854.

34. Quadlbauer S, Pezzei C, Beer T, Jurkowitsch J, Keuchel T, et al. (2019) Treatment of scaphoid waist nonunion by one, two headless compression screws or plate with or without additional extracorporeal shockwave therapy. Arch Orthop Trauma Surg 139(2): 281-293.

35. Notarnicola A, Moretti L, Tafuri S, Gigliotti S, Russo S, et al. (2010) Extracorporeal shockwaves versus surgery in the treatment of pseudoarthrosis of the carpal scaphoid. Ultrasound Med Biol 36(8): 1306-1313.

36. Birnbaum K, Wirtz DC, Siebert CH, Heller KD (2002) Use of extracorporeal shock-wave therapy (ESWT) in the treatment of non-unions. A review of the literature. Arch Orthop Trauma Surg 122(6): 324-330.

37. Petrisor B, Lisson S, Sprague (2009) Extracorporeal shockwave therapy: A systematic review of its use in fracture management. Indian J Orthop 43(2): 161-167.

38. Willems A, Van der Jagt OP, Meuffels DE (2019) Extracorporeal shock wave treatment for delayed union and nonunion fractures: A systematic review. J Orthop Trauma 33(2): 97-103.

39. http://www.fysiosupplies.nl/media/PDF/ISMST_2009_Abstract_book. pdf

40.Schnurrer-Luke-Vrbanic T, Avancini-Dobrovic V, Sosa I, Cvijanovic O, Bobinac D (2018) VEGF-A expression in soft tissues repaired by shockwave therapy: Differences between modalities. J Biol Regul Homeost Agents 32(3): 583-588.

41. Diaz-Rodriguez L, Garcia-Marinez O, Arroyo-Morales M, RamosTorrecillas J, De Luna-Bertos E, et al. (2012) Effect of radial extracorporeal shock wave therapy on proliferation, cell viability and phagocytosis of human osteoblasts (MG63). Adv Sci Lett 17(1): 325-329.

42. Silk ZM, Alhuwaila RS, Calder JD (2012) Low-energy extracorporeal shock wave therapy to treat lesser metatarsal fracture nonunion: Case report. Foot Ankle Int 33(12): 1128-1132. 